\title{
Post-cesarean Surgical Complications: A Report of 149 Cases from the Department of General Surgery at Ignace Deen National Hospital of Conakry (Guinea)
}

\author{
Soumaoro Labile Togba ${ }^{1,}$, , Fofana Naby ${ }^{1}$, Kondano Saa Yawo ${ }^{1}$, Fofana Houssein ${ }^{1}$, Thea Kokolypé ${ }^{2}$, \\ Toure Aboubacar ${ }^{1}$, Diallo Aissatou Taran ${ }^{1}$ \\ ${ }^{1}$ Department of General Surgery, Ignace Deen National Hospital, Conakry, Guinea \\ ${ }^{2}$ Department of General Surgery, Regional Hospital, N’Zérékoré, Guinea
}

Email address:

soumaoro66@gmail.com (S. L. Togba)

${ }^{*}$ Corresponding author

\section{To cite this article:}

Soumaoro Labile Togba, Fofana Naby, Kondano Saa Yawo, Fofana Houssein, Thea Kokolypé, Toure Aboubacar, Diallo Aissatou Taran. Postcesarean Surgical Complications: A Report of 149 Cases from the Department of General Surgery at Ignace Deen National Hospital of Conakry (Guinea). Journal of Surgery. Vol. 9, No. 5, 2021, pp. 226-229. doi: 10.11648/j.js.20210905.12

Received: August 12, 2021; Accepted: September 3, 2021; Published: September 15, 2021

\begin{abstract}
Introduction: Cesarean section is one of the most commonly performed surgical procedures in obstetrics and is certainly one of the oldest operations in surgery. The aim of this work was to analyze the post-cesarean surgical complications collected in our department. Methods: This was a retrospective study covering a period of five years (January 2016 to December 2020) on a consecutive series of individual records of patients referred and managed for a post-Cesarean surgical complications in the general surgery department of the Ignace Deen National Hospital of Conakry. Cases of complications occurring within 30 days after cesarean section were included in this study. Results: We collected 149 cases of early surgical complications after cesarean section. The mean age of the patients was $29.25 \pm 03$ years. The majority of the patients were women from poor social backgrounds $(74,50 \%)$. Peritonitis $(51.01 \%)$, intestinal obstruction $(19.46 \%)$ and surgical site infection $(16.78 \%)$ were the most noted complications. In the management of these complications, relaparotomy was necessary in $79.19 \%$ of cases. The overall mortality rate was $14.09 \%$. Conclusion: The reinforcement of prenatal consultation, the continuous training of health care personnel, and the improvement of the technical facilities of our hospitals are desired to reduce these complications.
\end{abstract}

Keywords: Cesarean Section, Early Surgical Complications, Management, Conakry, Guinea

\section{Introduction}

Cesarean section is one of the most commonly performed surgical procedures in obstetrics and is certainly one of the oldest operations in surgery $[1,2]$. Although often considered wrongly by young practitioners as a routine procedure, and in spite of the immense progress made in operative techniques and anesthesiology, cesarean section continues to cause serious maternal complications sometimes putting at risk the vital prognosis and the obstetrical outcome of the woman [2, 3]. Since the introduction of the policy of free cesarean section in some low income countries, the rate of cesarean section has considerably increased $[4,5]$. However, to our knowledge little is known regarding the morbidity and mortality related to this procedure in African region.

The aim of this work was to analyze the post cesarean surgical complications collected in our department.

\section{Patients and Methods}

This was a retrospective study covering a five-year period (January 2016 to December 2020) of a consecutive series of individual records of patients referred and managed for a post-Cesarean surgical complication in the general surgery department of the Ignace Deen National Hospital in Conakry. This is a university referral hospital, which receives patients in first-line consultation or referred from peripheral health 
facilities. Cases of complications occurring within 30 days after the cesarean section were included in this study. The parameters studied were the sociodemographic profile of the patients, clinical aspects, types of complications, therapeutic methods and outcome. Qualitative data were presented in terms of frequency or percentage and quantitative data were evaluated as an average.

\section{Results}

From the archives concerning the period of our study, we collected 149 records of patients referred to surgery and managed for an early surgical complication after cesarean section. The characteristics of these patients are presented in Table 1. In the series, 115 patients $(77.18 \%)$ underwent emergency surgery compared to 34 cases $(22.82 \%)$ scheduled. The majority of women $(63.09 \%)$ were referred from a health center after failure of vaginal delivery. The indications for cesarean section are grouped in Table 2 and Figure 1 illustrates the location of the procedure. In the series, $63.76 \%$ $(n=95)$ of the cesarean sections were performed by obstetric \& gynecology residents. The incision was low pubic (Pfannenstiel) in 98 cases $(65.77 \%)$ and median subumbilical in 51 cases $(34.23 \%)$. Table 3 shows the distribution according to the type of complication. Relaparotomy was necessary in 118 cases $(79.19 \%)$ and consisted of: peritoneal cleansing $(70.47 \%)$, resection of flanges $(19.46 \%)$, ileal debridement and suture $(8.72 \%)$, bladder debridement and suture $(4.03 \%)$ and wall repair (16.78). In all cases, antibiotic therapy based on ceftriaxone followed by amoxicillin+clavulanic acid and metronidazone were administered.

The outcome was favorable in 115 cases $(77.18 \%)$. We noted 13 cases $(8.72 \%)$ of incisional hernia and 21 deaths $(14.09 \%)$.

The average duration of hospitalization was $16.35 \pm 11$ days with extremes of 4 and 49 days).

Table 1. Characteristics of the population.

\begin{tabular}{|c|c|c|}
\hline Characteristics & Number $(n=149)$ & Percentage \\
\hline \multicolumn{3}{|l|}{ Age: } \\
\hline \multicolumn{3}{|c|}{ Mean age: $29,25 \pm 03$ years old; extremes: 15 and 41 years old } \\
\hline \multicolumn{3}{|l|}{ Provenance: } \\
\hline Rural areas & 82 & 55,03 \\
\hline Urban areas & 67 & 44,97 \\
\hline \multicolumn{3}{|l|}{ Occupation: } \\
\hline Housewife & 63 & 42,28 \\
\hline Informal sector & 48 & 32,21 \\
\hline Employee & 26 & 17,46 \\
\hline Student & 12 & 08,05 \\
\hline \multicolumn{3}{|l|}{ Marital status: } \\
\hline Married & 94 & 63,09 \\
\hline Single & 55 & 36,91 \\
\hline \multicolumn{3}{|l|}{ Parity: } \\
\hline Primiparous & 75 & 50,34 \\
\hline Poor & 53 & 35,57 \\
\hline Multiparous & 21 & 14,09 \\
\hline \multicolumn{3}{|c|}{ Up-to-date prenatal consultation: } \\
\hline Yes & 58 & 38,93 \\
\hline No & 91 & 61,07 \\
\hline
\end{tabular}

Table 2. Indications for cesarean section.

\begin{tabular}{lll}
\hline Indications & Number & Percentage \\
\hline Fetal distress & 57 & 38,26 \\
In utero death & 37 & 24,83 \\
Scarred uterus & 33 & 22,15 \\
Abnormal presentation & 12 & 8,05 \\
Excess of term & 05 & 3,36 \\
Gemellar dystocia & 03 & 2,01 \\
unkown & 02 & 1,34 \\
Total & 149 & 100 \\
\hline
\end{tabular}




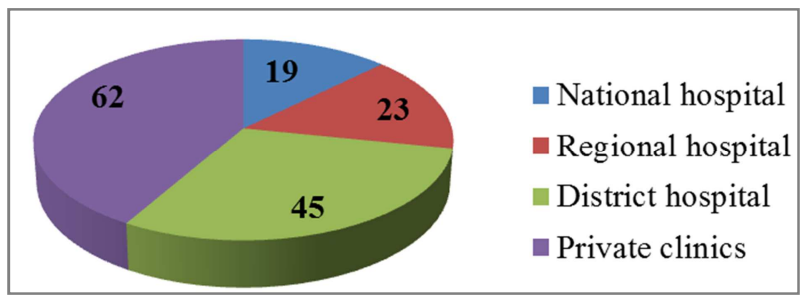

Figure 1. Distribution by the location of Cesarean section.

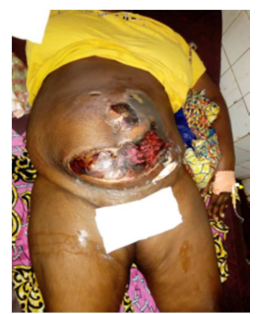

Figure 2. Abdominal wall infection with extensive necrose in a 32-year old woman after cesarean section performed in a district hospital.

Table 3. Distribution by type of surgical complications.

\begin{tabular}{lll}
\hline Type of complication & Number & Percentage \\
\hline Peritonitis & 76 & 51,01 \\
Intestinal obstruction & 29 & 19,46 \\
Wall infection + Evisceration & 25 & 16,78 \\
Enterocutaneous fistula & 13 & 8,72 \\
Vesico-cutaneous fistula & 6 & 4,03 \\
Total & 149 & 100 \\
\hline
\end{tabular}

\section{Discussion}

The rate of cesarean section has been steadily increasing over the last three decades and its incidence has risen from 5 to about 25 or even more than $50 \%$ in some countries [1]. In the African context, this rate has increased considerably since the introduction of the policy of free cesarean section in some countries. In a study carried out in a health district in Mali, the cesarean section rate increased from $46.90 \%$ before the introduction of free cesarean sections to $60.40 \%$ after [4]. In Burkina Faso, this rate was $36.1 \%$ in 2015 in the obstetrics gynecology department of the Yalgado Ouédraogo University Hospital [5]. In Morocco the cesarean section rate increased from $2 \%$ in 1992 to $16 \%$ in 2011 [1]. Indeed, the availability of free cesarean section kits in our hospitals could lead many parturients to voluntarily choose cesarean section for fear of the pain of vaginal delivery; on the other hand, doctors would tend to reduce the indications of cesarean section to shorten the time and constraints related to monitoring labor. A multicenter study could provide more insight into the factors associated with the increased cesarean section rate in Africa.

The risk and safety associated with cesarean section differ from one place to another; and maternal complications remain high, sometimes putting at risk the vital prognosis and obstetrical outcome of the woman [2, 3]. Among these complications, those requiring surgical management are of concern in our context. They are frequently observed in lowincome women. In our series, these were housewives or women working in the informal sector, primiparous with limited access to prenatal consultation (38.93\%). In the study by Benkirane $\mathrm{S}$ et al [1]. $81.7 \%$ of pregnant women were not followed up.

Surgical complications are common in emergency cesarean sections $[1,2,5,6]$ performed by general practitioners or residents $[2,5]$ in private clinics or district hospitals. The indications remain dominated by fetal suffering, in utero death and dystocia [2, 4]. In our series, $63.09 \%$ of women arrived at the hospital after failed vaginal delivery either at home or in a peripheral health center. This same finding has been observed in other African series [2,5]. Indeed, despite the policy of free obstetrical care in our country since 2010 [7], many women still do not have access to a regular prenatal consultation and the rate of home deliveries remains high.

In our context, early surgical complications are dominated by deep infections (peritonitis) and wound infections (surgical site infection, figure 2) [1-6]. In fact, women who give birth by cesarean section are 5 to 20 times more likely to develop an infection than those who give birth by vaginal delivery [8, 9]. In particular, surgical site infection corresponds to contamination of the wound by bacteria of cutaneous or vaginal origin [1]. This calls for a reinforcement of perioperative asepsis and antisepsis measures in our hospitals.

Complications such as enterocutaneous or vesicocutaneous fistulas following visceral lesions are often observed during iterative cesarean sections (19 cases in our study).

The management of these complications requires active resuscitation and often a re-intervention either to remove an infectious focus or to treat a possible visceral injury. This leads to a prolongation of the duration of hospitalization, dissatisfaction of patients, higher treatment costs [10] and above all to high morbidity and mortality $[5,11,12]$. The high rate of death $(14.09 \%)$ observed in our study could be explained by the delay in referral of patients to the surgical service on the one hand, but above all by the weakness of our resuscitation resources on the other. Indeed, in the absence of a health insurance system, the costs related to the management of these complications of cesarean section are borne by the family and are not reimbursable. Despite the free exemption on maternity care including cesarean section in various parts of Africa and Asia maternal and perinatal mortality still remains a major public health concern [13-15]. In our context, we experienced recurrent stock outs of drugs and supplies, low staff motivation and disruption of referral system $[4,5,7]$.

\section{Conclusion}

Cesarean section, although often considered a commun surgical procedure, can lead to serious surgical complications with a high morbidity and mortality rate. The reinforcement of prenatal consultation, the continuous training of health 
care personnel, and the improvement of the technical facilities of our hospitals are desired to reduce these complications.

\section{Conflict of Interest}

Authors do not have any conflict of interest.

\section{References}

[1] Benkirane S, Saadi H, Mimouni A (2017). Epidemiological profile of maternal complications related to cesarean section at the Al Farabi Hospital in Oujda Pan African Medical Journal 27: 108. doi: 10.11604/pamj.2017.108.10036.

[2] Ngowa JDK, Ngassam A, Fouogue JT, Metogo J, Medou A, Kasia JM (2015) Early maternal complications of cesarean section: report of 460 cases in two university hospital of Yaoundé, Cameroun. Pan African Medical Journal 21: 265 doi: 10.11604/pamj.2015.21.265.6967.

[3] Anonymous Déclaration de l'OMS sur les taux de césarienne, www.who.int/reproductivehealth.

[4] Diawara A, Sangho H, Tangara I, Cissé MO, Traoré MN, Konaté S (2014) Postopérative complications and free cesarean section in Mali: case of a health district. Mali Medical 24 (1): 40-43.

[5] Sawadogo YA, Komboigo E, Kiemtore S, Zamane H, Ouedraogo I, Kain DP, Toure B, Ouedraogo C, Ouedraogo A, Thieba B (2019) Parietal suppurations after cesarean section at the Yalgado Ouédraogo University Hospital, Burkina Faso: epidemiological clinical, therapeutic and prognostic aspects Pan African Medical Journal 32: 35 . doi: 10.11604/pamj.2019.32.35.17167.

[6] Sway A, Nthumba P, Solomkin J, Tarchini G, Gibbs R, Ran Y, Wanyoro A (2019). Burden of surgical site infection following cesarean section in sub-Saharan Africa: a narrative review International Journal of Women's Health 11: 309-318.

[7] Delamou A, Camara BS, Sidibé S et al. (2015) Free Obstetric
Care: Opinions of beneficiaries in Conakry city (Guinea) Guinée Médicale 87 (2): 4-11.

[8] Conroy K, Koenig AF, Yu Y, Courtney A, Lee HJ, Morwitz ER (2012) Infectious morbidity after cesarean delivery: 10 strategies to reduce risk. Rev obstet Gynecol. 5 (2): 6977.

[9] Farret TCF, Dallé J, Monteiro V, Riche CVW, Antonello VS (2015) Risk factors for surgical site infection following cesarean section in a Brazilian Women's Hospital: a casecontrol study. Braz J Infect Dis 19 (2): 113-7.

[10] Vjosa A. Zejnullahu, Rozalinda Isjanovska, Zana Sejfija and Valon A. Zejnullahu (2019) Surgical site infections after cesarean sections at the University Clinical Center of Kosovo: rates, microbiological profile and risk factors. BMC Infectious Diseases 19: 752 https://doi.org/10.1186/s12879-019-4383-7.

[11] Holmer H, kamara MM, Bolkan HA et al. (2019) The rate and perioperative mortality of caesarean section in Sierra Leone. BMJ Global Health; 0016505. Doi: 10.1136/bmjgh-2019001605 .

[12] Kinenkinda X, Mukulu O, Chenge F, Kakudji P (2017) Risk factors for maternal and perinatal mortality among women undergoing cesarean section in Lubumbashi, Democratic Republic of Congo II. Pan African Medical Journal; 26: 208 doi: 10.11604/pamj.2017.26.208.12148.

[13] Lang'at E, Mwanri L and Temmerman M (2019) Effects of implementing free maternity service policy in Kenya: an interrupted time series analysis. BMC Health Services Research 19: 645 https://doi.org/10.1186/s12913-019-4462-x.

[14] Kranti Suresh Vora, Sandul Yasobant, Raja Sengupta, Ayesha De Costa, Ashish Upadhyay, DileepV. Mavalankar (2015). Options for Optimal Coverage of Free C- Section Services for Poor Mothers in Indian State of Gujarat: Location Allocation Analysis Using GIS. PLoS ONE 10 (9): e0137122. doi: 10.1371/journal.pone.0137122.

[15] Alkema L, Chou D, Hogan D, et al. Global, regional, and national levels and trends in maternal mortality between 1990 and 2015, with scenario-based projections to 2030: a systematic analysis by the UN maternal mortality estimation inter-agency group. Lancet. 2016; 387 (10017): 462-474. 